\title{
Viewpoint \\ Microarray technology and its effect on breast cancer (re)classification and prediction of outcome
}

\author{
Fatima Cardoso \\ Department of Medical Oncology, Translational Research Unit, Jules Bordet Institute, Brussels, Belgium \\ Corresponding author: Fatima Cardoso (e-mail: fatima.cardoso@bordet.be) \\ Published: 9 October 2003
}

Breast Cancer Res 2003, 5:303-304 (DOI 10.1186/bcr732)

(C) 2003 BioMed Central Ltd (Print ISSN 1465-5411; Online ISSN 1465-542X)

\section{Introduction}

With screening mammography becoming more widely used throughout Europe, a growing proportion of women diagnosed with breast cancer present with earlier disease stages. Although these women can enjoy long-term survival, $20 \%-30 \%$ will relapse and die from their disease. There is, however, a great deal of controversy related to the optimal definition of a low/minimal versus a moderate/high risk of relapse for women with node negative breast cancer. Many oncologists rely on the guidelines issued by experts following consensus conferences [1]. Consequently, only $15 \%$ to $20 \%$ of patients are assigned to a "low/minimal risk" subset and this may result in many women with early breast cancer being over-treated - a phenomenon that not only exposes these women to unnecessary toxicity, but also increases the economic burden of this frequent disease on society.

\section{Gene expression profiles}

Microarray technology is fundamentally changing our understanding of cancer biology at the molecular level. Use of microarrays for genome-wide expression profiling provides a more refined molecular classification of human cancers and has reinforced the notion that breast cancer is a heterogeneous disease. This knowledge has great potential for a better selection of patients in need of adjuvant therapy as well as for tailored treatment approaches [2].

A landmark study in this area is the work of Sorlie and colleagues [3] that proposed a new classification of breast cancer clearly separating endocrine non-responsive from endocrine-responsive disease. Recently, Sorlie and coworkers have confirmed their results in an independent set of breast tumors, refining previously defined sub-types of breast tumors that could be distinguished by their distinct patterns of gene expression [4]. Other landmark studies $[5,6]$, with potentially huge implications for clinical management of breast cancer, describe the work of the Amsterdam group. These investigators identified a 70-gene poor-prognosis signature that can accurately predict relapse-free sur- vival in both node-negative and node-positive breast cancer. Interestingly, the number of low-risk patients who can be spared adjuvant chemotherapy appears to be markedly increased (about 30\%) when the prognosis-genetic signature is used instead of the commonly used consensus guidelines. Although impressive and interesting, this work has some weakness, such as the retrospective nature of the study, the small sample size, and the fact that only young women were selected $($ all $<52)$ all of whom were treated in one hospital. This makes extrapolations to other age groups and other regions difficult [7]. It also has to be born in mind, that microarray is a new and expensive technology that, although evolving rapidly, needs to be fully standardized in order to be reproducible across different laboratories.

Therefore, these interesting results needed to be duplicated in an independently run study and then validated in a large, independent, prospective trial, before being applicable in clinical practice [8]. This has recently been done by Sotiriou and colleagues [9] who analyzed RNAs from an independent set of 99 breast cancer patients with known clinical outcome. The results concur with those of the earlier studies, despite differences in patient populations, treatments used and technology platforms employed. This study found that the ER status of the tumor was, indeed, the most important discriminator of expression subtypes, confirming that ER biology plays a central role in breast carcinogenesis. Tumor grade was found to play a secondary role. Unsupervised hierarchical clustering analysis segregated these 99 tumors into two main clusters based on their basal (predominantly ER negative) and luminal (predominantly ER positive) characteristics; within each of these clusters smaller subgroups were identified, characterized by distinct gene expression signatures involving different oncogene-specific pathways. As in earlier studies, the molecular signature subgroups showed expected differences in survival, with a better outcome in the luminal group. In addition, the authors identified a group of 485 different probe elements statistically associated with survival $(P<0.05)$. Other clinical fea- 
tures, such as lymph node positivity, menopausal status, and tumor size, were not strongly reflected in the expression patterns obtained in this investigation. Thus, the evidence to date suggests that molecular profiling can substantially refine cancer prognosis, perhaps well beyond what is possible with other clinical indicators.

Another preliminary, but important, finding of this study is that molecular signatures might be generalized to populations other than those in which they were initially developed, and across multiple microarray platforms and technologies. Sotiriou and colleagues found substantial evidence that the 231 expressed genes reported as separating survival groups in the Van't Veer study [5] have prognostic relevance in a different, heterogeneous population of node positive and node negative patients treated with adjuvant therapy.

\section{Conclusions and future directions}

Given the high potential of gene expression profiling to change clinical practice, it is now important to validate this new prognostic tool in a large, independent and prospective trial. Such a study - the MINDACT trial - is already in an advanced stage of preparation and will be run through the Breast International Group network, coordinated by the European Organization for Research and Treatment of Cancer (EORTC), and funded by the European Commission under the Framework VI Programme. MINDACT will evaluate the role of the gene prognosis signature in the selection of good prognosis versus bad prognosis node negative breast cancer patients and aims to identify a subgroup of these patients that can be spared adjuvant chemotherapy.

Despite their importance, translating these outstanding advances in basic biological knowledge into clinical benefits in the prevention, diagnosis and treatment of breast cancer has been difficult and slow.

In the present era, where we are rapidly moving from empirical towards molecular oncology in cancer management, only large, well-conducted, biologically-based prospective trials will allow us to reach the needed conclusions and to shorten the lapse of time for the clinical application of new markers and techniques.

\section{Competing interests}

FC is part of the research team working on the MINDACT trial, which is funded by the European Commission.

\section{References}

1. Goldhirsch A, Wood WC, Gelber RD, Coates AS, Thürlimann B, Senn HJ: Meeting Highlights: Updated International Expert Consensus on the Primary Therapy of Early Breast Cancer. J Clin Oncol 2003, 21:3357-3365.

2. Sotiriou C, Powles TJ, Mitch Dowsett M, Jazaeri AA, Feldman AL, Assersohn L, Gadisetti C, Libutti SK, Liu ET: Gene expression profiles derived from fine needle aspiration correlate with response to systemic chemotherapy in breast cancer. Breast Cancer Res 2002, 4:R3.

3. Sørlie T, Perou CM, Tibshirani R, Aas T, Geisler S, Johnsen H Hastie T, Eisen MB, van de Rijn M, Jeffrey SS: Gene expression patterns of breast carcinomas distinguish tumor subclasses with clinical implications. Proc Natl Acad Sci USA 2001, 98: 10869-10874.

4. Sørlie T, Tibshirani R, Parker J, Hastie T, Marron J. S, Nobel A, Deng S, Johnsen H, Pesich R, Geisler S, Demeter J, Perou CM, Lønning $P E$, Brown PO, Børresen-Dale A-L, Botstein D: Repeated observation of breast tumor subtypes in independent gene expression data sets. Proc Natl Acad Sci USA 2003, 100:8418-8423.

5. van't Veer $L$, Dai $H$, van de Vijver MJ, He YD, Hart AAM, Mao M, Peterse HL, Van der Kooy K, Marton MJ, Witteveen AT, Schreiber GJ, Kerkhoven RM, Roberts C, Linsley PS, Bernards R, Friend $\mathrm{SH}$ : Gene expression profiling predicts clinical outcome of breast cancer. Nature 2002, 415:530-536.

6. Van de Vijver MJ, He YD, Van't Veer LJ, Dai H, Hart AAM, Voskuil DW, Schreiber GJ, Peterse JL, Roberts C, Marton MJ, Parrish M, Atsma D, Witteveen A, Glas A, Delahaye I, Van der Velde T, Bartelink H, Rodenhuis S, Rutgers ET, Friend SH, Bernards R: A gene-expression signature as a predictor of survival in breast cancer. New Engl J Med 2003, 347:1999-2009.

7. Gruvberger SK, Ringnér M, Edén P, Borg A, Fernö M, Peterson C, Meltzer PS: Expression profiling to predict outcome in breast cancer: the influence of sample selection. Breast Cancer Res 2003, 5:23-26.

8. van't Veer $L J$, Dai $H$, van de Vijver MJ He YD, Hart AAM, Bernards $\mathrm{R}$, Friend $\mathrm{SH}$ : Expression profiling predicts outcome in breast cancer. Breast Cancer Res 2003, 5:57-58.

9. Sotiriou C, Neo SY, McShane LM, Korn EL, Long PM, Jazaeri A, Martiat P, Fox SB, Harris AL, Liu ET. Breast cancer classification and prognosis based on gene expression profiles from a population-based study. Proc Natl Acad Sci USA 2003, 100: 10393-10398

\section{Note}

This article is based on papers highlighted by Faculty of 1000 (http://www.facultyof1000.com/start.asp), a web-based literature awareness service. Faculty of 1000 evaluations available for articles cited in this report may be viewed at: http://www.breast-cancer-research.com/reports/bcr732.asp

\section{Correspondence}

Fatima Cardoso, MD, Department of Medical Oncology, Translational Research Unit, Jules Bordet Institute, Boulevard de Waterloo, 125 1000 Brussels. Tel: + 322541 3082; fax: + 322541 3199; e-mail: fatima.cardoso@bordet.be 